\title{
Hubungan konsumsi susu dengan fungsi kognitif pada lansia
}

\author{
Derry Arkan Prabowo, ${ }^{1}$ Fransisca Chondro ${ }^{2}$
}

\begin{abstract}
ABSTRAK
\section{LATAR BELAKANG}

Pada lansia, fungsi kognitif adalah salah satu faktor penting yang mempengaruhi kemampuannya dalam menjalankan aktivitas sehari-hari. Adanya gangguan pada fungsi kognitif akan menimbulkan disfungsi sehingga dapat menurunkan kualitas hidup lansia. Beberapa faktor yang dapat mempengaruhi fungsi kognitif pada lansia adalah penuaan, penyakit metabolik dan nutrisi. Banyak sekali asupan nutrisi yang berpengaruh terhadap fungsi kongitif, salah satunya adalah susu. Sampai saat ini telah dilakukan beberapa penelitian terkait hubungan antara konsumsi susu dengan fungsi kognitif pada lansia namun didapatkan hasil yang kontradiktif. Oleh karena itu, peneliti tertarik untuk mengetahui lebih lanjut hubungan antara konsumsi susu dan fungsi kognitif pada lansia.
\end{abstract}

\section{METODE}

Penelitian cross-sectional dengan desain observasional analitik ini dilakukan di Posyandu Kelurahan Krendang, Jakarta Barat pada Bulan Agustus-Desember 2019 dengan melibatkan 135 responden. Kriteria inklusi pada penelitian ini adalah berusia minimal 60 tahun, tidak memiliki gangguan dalam membaca dan menulis, tidak mengalami gangguan pendengaran serta bersedia menjadi responden, sedangkan kriteria eksklusinya adalah lansia yang telah didiagnosis menderita hipertensi dan diabetes mellitus. Dalam wawancara terpimpin dengan setiap responden didapatkan karakteristik sosiodemografis (usia, jenis jelamin, dan pendidikan), tingkat konsumsi susu diukur dengan kuesioner susu yang diadaptasi dari Naruki Kitano, dan penilaian fungsi kognitif dengan kuesioner Montreal Cognitive Assesment Indonesia. Analisis data menggunakan uji statistik dengan tingkat kemaknaan $\alpha=0.05$.

\section{HASIL}

Didapatkan responden yang memiliki kebiasaan mengonsumsi susu adalah sebesar $51.9 \%$, yang mengalami gangguan fungsi kognitif adalah sebanyak $87.4 \%$, dan pada uji bivariat kedua variabel didapatkan $\mathrm{p}=0.660$.

\section{KESIMPULAN}

Pada penelitian ini dapat disimpulkan tidak terdapat hubungan yang bermakna antara konsumsi susu dan fungsi kognitif.

Kata kunci: lanjut usia, fungsi kognitif, susu
${ }^{1}$ Program Studi Kedokteran, Fakultas Kedokteran Universitas Trisakti, Jakarta, Indonesia ${ }^{2}$ Departemen Ilmu Faal, Fakultas Kedokteran Universitas Trisakti, Jakarta, Indonesia

\section{Korespondensi:}

Fransisca Chondro

Departemen Ilmu Faal, Fakultas

Kedokteran Universitas Trisakti, Jakarta, Indonesia

Jalan Kyai Tapa (Kampus B)

Usakti, Grogol, Indonesia 11440

Email:

fransisca_chondro@trisakti.ac.id

J Biomedika Kesehat 2021;4(4):148156

DOI: 10.18051/JBiomedKes.2021. v4.148-156

pISSN: 2621-539X / eISSN: 2621-5470

Artikel akses terbuka (open access) ini didistribusikan di bawah lisensi Creative Commons Attribution 4.0 International (CC-BY 4.0) 


\section{ABSTRACT}

\section{Relationship between milk consumption and cognitive function in the elderly}

\section{BACKGROUND}

Cognitive function in the elderly is one of the factors that affect their ability to carry out daily activities. Impaired cognitive function causes dysfunction and as a result can decrease their quality of life. Some factors that can affect cognitive function are aging, metabolic diseases and nutrition, such as milk consumption. Previous research regarding milk consumption and cognitive function in the elderly reported contradictory results. Hence, the purpose of this study was to determine the relationship between milk consumption and cognitive function in the elderly.

\section{METHODS}

This cross-sectional study with analytic observational design, took place at Posyandu, Krendang Urban Village, West Jakarta on August-December 2019 with a total of 135 participants. The inclusion criteria were elderly aged 60 years or above, don't have any impairment in reading, writing, hearing, and willing to sign the informed consent, while the exclusion criterion was elderly diagnosed with high blood pressure or diabetes mellitus. From one-onone interview, data taken were respondents' characteristics, milk consumption assessed using milk questionnaire adapted from Naruki Kitano, and cognitive function assessed using the Montreal Cognitive Assessment Indonesia questionnaire. Data analysis used statistic tests with significance level $\alpha=0.05$.

\section{RESULTS}

In this study, $51.9 \%$ participants had a habit of drinking milk, $87.4 \%$ participants had impaired cognitive function, and the results of bivariate analysis showed $p$ value $=0.660$.

\section{CONCLUSION}

From this study, it can be concluded that there is no significant relationship between milk consumption and cognitive function.

Keywords: elderly, cognitive function, milk

\section{PENDAHULUAN}

Pada lansia, fungsi kognitif adalah salah satu faktor penting yang mempengaruhi kemampuannya dalam menjalankan aktivitas sehari-hari. Adanya gangguan pada fungsi kognitif akan mengakibatkan gangguan dalam menjalankan aktivitas sehari-hari. Gangguan fungsi kognitif yang paling awal adalah mudah lupa (Forgetfulness) yang dapat berkembang menjadi gangguan kognitif ringan (Mild Cognitive Impairment) ataupun gangguan kognitif berat yakni demensia. ${ }^{(1,2)}$ Jumlah populasi lansia di Indonesia pada tahun 2017 diperkirakan sebanyak 23.6 juta jiwa atau $9.03 \%$ dari seluruh penduduk Indonesia, dan jumlah ini diperkirakan akan terus bertambah hingga mencapai 40.95 juta jiwa di tahun 2030. ${ }^{(3)}$ Peningkatan jumlah penduduk lansia ini mengakibatkan peningkatan prevalensi penyakit terkait usia seperti demensia dan gangguan kognitif lainnya. Jumlah penderita demensia di Kawasan Asia Pasifik pada tahun 2015 berjumlah 23 juta orang dan jumlah ini diperkirakan akan terus bertambah. Data dari Direktorat Jenderal Pelayanan Medik Kementrian Kesehatan Republik Indonesia, diketahui bahwa prevalensi gangguan fungsi kognitif pada lansia di Indonesia mencapai $32.4 \%{ }^{(4,5)}$

Terdapat beberapa faktor yang dapat mempengaruhi fungsi kognitif pada lansia seperti usia, jenis kelamin, nutrisi, serta penyakit metabolik seperti hipertensi dan diabetes mellitus. ${ }^{(6,7,8)}$ Salah satu nutrisi yang juga dapat mempengaruhi fungsi kognitif adalah susu. Diduga kandungan fosfolipid pada membran globul susu dapat mempengaruhi fungsi kognitif. ${ }^{(9)}$ Selain itu, di dalam produk susu juga terkandung zat gizi lainnya berupa makronutrien dan mikronutrien yang juga bermanfaat bagi kesehatan tubuh dan fungsi kognitif kita. ${ }^{(10,11)}$ 
Sampai saat ini, belum ada penelitian mengenai konsumsi susu dengan fungsi kognitif di Indonesia. Di negara lain, sudah ada beberapa penelitian terkait hal ini namun masih didapatkan hasil yang kontradiktif. Uji meta-analisis yang dilakukan oleh Lei et al menyimpulkan bahwa dari 7 studi yang ditelaah, konsumsi produk susu dikaitkan dengan penurunan resiko kejadian penyakit Alzheimer. Selain itu, pada responden dengan tingkat konsumsi susu tinggi memiliki resiko gangguan kognitif lebih rendah $28 \%$ dibandingkan dengan responden dengan tingkat konsumsi susu rendah. ${ }^{(12)}$ Penelitian oleh Ozawa et al juga menyatakan bahwa konsumsi susu yang tinggi dikaitkan dengan penurunan resiko penyakit Alzheimer pada penduduk Jepang. ${ }^{(13)}$ Namun, studi yang dilakukan oleh Lee et al mendapatkan hasil yang berbeda yaitu tidak terdapat hubungan yang bermakna antara konsumsi susu dan penurunan fungsi kognitif. ${ }^{(14)}$ Penelitian lainnya oleh Petruski-Ivleva juga menyimpulkan bahwa konsumsi susu dikaitkan dengan penurunan fungsi kognitif dalam kurun waktu 20 tahun. ${ }^{(15)}$ Studi lain oleh Cuesta-Triana et al menyatakan bahwa hubungan antara konsumsi susu dan fungsi kognitif sangat kompleks serta dipengaruhi oleh jenis dan jumlah susu yang dikonsumsi. ${ }^{(16)}$ Adanya perbedaan hasil dan belum adanya penelitian serupa di Indonesia membuat peneliti tertarik untuk meneliti hubungan antara konsumsi susu dan fungsi kognitif pada lansia.

\section{METODE}

Penelitian ini merupakan studi cross-sectional dengan desain penelitian observational analitik. Penelitian dilakukan pada bulan Agustus hingga Desember tahun 2019 di Posyandu Kelurahan Krendang, Kecamatan Tambora, Jakarta Barat. Populasi penelitian yaitu seluruh lansia ( $\geq 60$ tahun) di Posyandu lansia Kelurahan Krendang yang bersedia untuk mengikuti penelitian. Kriteria inklusi pada penelitian iniyaitu berusia 60 tahun atau lebih, bersedia mengikuti penelitian dan pemeriksaan fungsi kognitif, tidak mengalami gangguan dalam membaca, menulis dan tidak memiliki gangguan pendengaran. Sedangkan kriteria eksklusinya adalah lansia yang telah terdiagnosis menderita diabetes melitus dan hipertensi.

Pemilihan sampel dilakukan secara consecutive non random sampling dan semua lansia yang memenuhi kriteria inklusi dan eksklusi diambil sebagai responden. Melalui wawancara terpimpin didapatkan data sosiodemografis pasien. Pada penelitian ini, untuk menilai fungsi kognitif digunakan instrumen berupa kuesioner Montreal Cognitive Assesment versi indonesia (MoCAIna) dengan fungsi kognitif normal bila mendapat skor 26-30, sedangkan hasil skor $<26$ maka lansia tersebut mengalami gangguan fungsi kognitif. ${ }^{(17,18)}$ Kuesioner yang diadaptasi dari penelitian Naruki Kitano digunakan untuk menilai konsumsi susu, dan banyaknya susu yang dikonsumsi diukur dalam satuan mililiter digunakan alat bantu berupa foto gelas. Jadi pada lansia diperlihatkan contoh ukuran gelas lalu diminta untuk membandingkan jumlah susu yang dikonsumsi dengan takaran gelas tersebut. Hasil interpretasinya adalah jika lansia tidak pernah mengonsumsi susu dalam seminggu maka termasuk kategori tidak mengonsumsi susu, jika lansia mengonsumsi 
susu sebanyak 0-1049 ml/minggu maka akan masuk ke dalam kategori kelompok konsumsi susu yang rendah, dan jika $\geq 1050 \mathrm{ml} / \mathrm{minggu}$ maka lansia masuk dalam kelompok konsumsi susu yang tinggi. Data yang didapat kemudian dianalisis dengan uji Chi-square dengan tingkat kemaknaan $\alpha=0.05 .^{(19,20)}$

\section{HASIL}

Tabel. 1 Data karateristik responden

\begin{tabular}{|c|c|c|}
\hline Variabel & $\mathbf{n}$ & $\%$ \\
\hline \multicolumn{3}{|l|}{ Usia } \\
\hline Lanjut usia (60-74 tahun) & 117 & 86.7 \\
\hline Lanjut usia tua (75-90 tahun) & 18 & 13.3 \\
\hline \multicolumn{3}{|l|}{ Jenis Kelamin } \\
\hline Perempuan & 94 & 69.6 \\
\hline Laki-laki & 41 & 30.4 \\
\hline \multicolumn{3}{|l|}{ Konsumsi Susu } \\
\hline Tidak mengonsumsi & 65 & 48.1 \\
\hline $\begin{array}{l}\text { Konsumsi rendah }(0-1049 \mathrm{ml} / \\
\text { minggu })\end{array}$ & 54 & 40.0 \\
\hline $\begin{array}{l}\text { Konsumsi tinggi }(\geq 1050 \mathrm{ml} / \\
\text { minggu })\end{array}$ & 16 & 11.9 \\
\hline \multicolumn{3}{|l|}{ Fungsi Kognitif } \\
\hline Normal (skor 26-30) & 17 & 12.6 \\
\hline $\begin{array}{l}\text { Gangguan fungsi kognitif } \\
\text { (skor } \leq 25)\end{array}$ & 118 & 87.4 \\
\hline \multicolumn{3}{|l|}{ Pendidikan } \\
\hline Tidak sekolah & 10 & 7.4 \\
\hline Pendidikan dasar (SD) & 100 & 74.1 \\
\hline $\begin{array}{l}\text { Pendidikan menengah (SMP/ } \\
\text { SMA/STM) }\end{array}$ & 25 & 18.5 \\
\hline
\end{tabular}

Keterangan: $\mathrm{n}=$ jumlah; $\%=$ persentase

Dari Tabel 1 diketahui bahwa dari 135 responden, lebih dari $86 \%$ berusia kurang dari 75 tahun dengan rata-rata usia responden 66.61 tahun. Selain itu, dapat kita lihat pula bahwa sebagian besar responden berjenis kelamin perempuan (yakni sebesar 69.6\%). Sedangkan untuk tingkat pendidikan, lebih dari 74\% responden memiliki tingkat pendidikan rendah, yakni lulusan Sekolah Dasar.

Pemeriksaan fungsi kognitif responden menggunakan kuesioner Montreal
Cognitive Assesment versi Indonesia (MocaIna) dan didapatkan bahwa sebanyak 118 responden (87.4\%) memiliki gangguan fungsi kognitif dengan nilai rata-rata skor Moca-Ina adalah 18.21. Untuk pengukuran tingkat konsumsi susu digunakan kuesioner yang diadaptasi dari Naruki Kitano. Setelah dilakukan pengukuran, didapatkan bahwa hampir separuh responden, yaitu sebanyak $48.1 \%$ ternyata tidak mengonsumsi susu.

Tabel 2 menyajikan hasil analisis bivariat antara karakteristik responden dan fungsi kognitif. Dari uji hubungan antara usia dan fungsi kognitif didapatkan nilai $\mathrm{p}>0.05$ atau dapat disimpulkan tidak terdapat hubungan yang bermakna secara statistik diantara variabel tersebut. Namun, jika kita menelaah data tersebut berdasarkan tiap kelompok usia, dapat kita lihat bahwa pada kelompok usia yang lebih tua terlihat jumlah responden yang mengalami gangguan kognitif lebih banyak, yaitu pada kelompok lanjut usia tua semua responden mengalami gangguan fungsi kognitif.

Pada uji hubungan antara jenis kelamin dan fungsi kognitif juga didapatkan hasil $\mathrm{p}>0.05$. Dari tabel dapat kita lihat bahwa baik pada responden perempuan ataupun laki-laki, jumlah responden yang mengalami gangguan fungsi kognitif jumlahnya kurang lebih sama, yaitu lebih dari $80 \%$ dari tiap jenis kelamin. Hasil berbeda didapatkan pada uji hubungan antara tingkat pendidikan dan fungsi kognitif dengan nilai $\mathrm{p}<0.05$ atau dengan kata lain terdapat hubungan yang bermakna secara statistik antara tingkat pendidikan dan fungsi kognitif. Dari Tabel 2 dapat kita lihat bahwa pada kelompok tingkat pendidikan rendah jumlah yang mengalami gangguan 
fungsi kognitif mencapai 95.4\%. Sedangkan untuk responden dengan tingkat pendidikan menengah, jumlah yang mengalami gangguan fungsi kognitif lebih rendah yakni sebanyak $52 \%$.

Pada uji statistik yang menilai hubungan antara konsumsi susu dengan fungsi kognitif didapatkan nilai $\mathrm{p}>0.05$ atau tidak terdapat hubungan yang bermakna secara statistik antara kedua variabel. Berdasarkan tabel dapat kita lihat bahwa pada setiap kelompok tingkat konsumsi susu, mayoritas responden mengalami gangguan fungsi kognitif. Bahkan kelompok tingkat konsumsi susu tinggi yang mengalami gangguan fungsi kognitifjumlahnya lebih banyak dibandingkan dengan responden yang tidak mengonsumsi susu yang mengalami gangguan fungsi kognitif.

\section{PEMBAHASAN}

Pada penelitian ini, pemeriksaan fungsi kognitif dengan kuesioner Moca-Ina pada lansia menunjukkan bahwa sebanyak $87.4 \%$ lansia mengalami gangguan fungsi kognitif dengan rata-rata skor Moca-Ina adalah 18.21. Hasil tersebut menunjukkan bahwa jumlah lansia yang mengalami penurunan fungsi kognitif di posyandu lansia Kelurahan Krendang lebih tinggi dibandingkan data dari Dirjen Pelayanan Kesehatan RI yang mengatakan prevalensi gangguan fungsi kognitif di Indonesia mencapai 32.4\%. Pada studi oleh Noor et al didapatkan kejadian gangguan fungsi kognitif pada lansia adalah sebesar 31.5\%. Studi lain oleh Tanjung et al mendapatkan hasil yang tidak terlalu jauh berbeda. Didapatkan kejadian gangguan fungsi kognitif sebesar $46.1 \% .^{(4,21)}$ Perbedaan hasil tersebut dapat disebabkan karena perbedaan dari instrumen yang digunakan untuk menilai fungsi kognitif. Pada penelitian Noor et al dan Tanjung et al fungsi kognitif dinilai menggunakan kuesioner Mini-mental State Examination, sedangkan pada penelitian ini digunakan kuesioner MoCA-Ina. Baik MMSE ataupun MoCA-Ina keduanya merupakan instrumen untuk mengukur fungsi kognitif. Penelitian oleh Ihara et al mendapatkan bahwa Japanese version of Montreal Cognitive Assesment (kuesioner adaptasi dari MoCA) lebih sensitif dalam proses skrining gangguan kognitif dibandingkan dengan MMSE. Studi oleh Dong et al juga menyatakan hal yang sama yaitu kuesioner MoCA lebih dapat mendeteksi adanya gangguan kognitif pada pasien dibandingkan dengan MMSE. ${ }^{(22,23)}$

Hasil uji exact fisher antara usia dengan fungsi kognitif menunjukkan hasil tidak bermakna dengan nilai $\mathrm{p}=0.074$. Sebelumnya telah dijelaskan bahwa usia dapat mempengaruhi fungsi kognitif karena proses penuaan yang mengakibatkan penurunan volume substansia grisea dan alba, serta gangguan transmisi sinyal di otak. Perubahan volume substansia grisea dikaitkan dengan proses kerusakan neuron yang terjadi. Diketahui bahwa atrofi yang terjadi pada otak akibat penuaan terlihat paling jelas pada lobus prefrontal dan hippocampus $(6,24,25)$ Pada penelitian ini, meskipun secara statistik didapatkan hasil tidak bermakna akan tetapi data analisis bivariat menunjukkan bahwa pada kelompok lanjut usia tua (74-90 tahun) jumlah responden yang mengalami gangguan fungsi kognitif lebih tinggi dibandingkan dengan kelompok usia lain.

Pada uji Chi-square antara jenis 
Tabel 2. Analisis bivariat

\begin{tabular}{|c|c|c|c|c|c|}
\hline \multirow{3}{*}{ Variabel } & \multicolumn{4}{|c|}{ Fungsi Kognitif } & \multirow{3}{*}{ Nilai $p$} \\
\hline & \multicolumn{2}{|c|}{ Normal } & \multicolumn{2}{|c|}{ Gangguan } & \\
\hline & $\mathrm{n}$ & $(\%)$ & $\mathrm{n}$ & $(\%)$ & \\
\hline \multicolumn{6}{|l|}{ Usia } \\
\hline Lanjut usia (60-74 tahun) & 17 & $(14.5)$ & 100 & $(86.5)$ & 0.074 \\
\hline Lanjut Usia tua (75-90 tahun) & 0 & $(0)$ & 10 & $(100)$ & \\
\hline \multicolumn{6}{|l|}{ Jenis kelamin } \\
\hline Perempuan & 10 & $(10.6)$ & 84 & $(89.4)$ & $0.451^{£}$ \\
\hline Laki-laki & 7 & $(17.1)$ & 34 & $(82.9)$ & \\
\hline \multicolumn{6}{|l|}{ Pendidikan } \\
\hline Tidak sekolah + & & & & & $0.000^{\infty £}$ \\
\hline Pendidikan dasar ( SD) & 5 & $(4.6)$ & 105 & $(95.4)$ & \\
\hline Pendidikan menengah (SMP/SMA/STM) & 12 & $(48)$ & 13 & $(52)$ & \\
\hline \multicolumn{6}{|l|}{ Konsumsi susu } \\
\hline Tidak mengonsumsi & 8 & $(12.3)$ & 57 & $(87.7)$ & \\
\hline Konsumsi Rendah (0-1049 ml/minggu) & 8 & $(14.8)$ & 46 & $(85.2)$ & $0.660^{\natural}$ \\
\hline Konsumsi Tinggi ( $\geq 1050$ ml/minggu) & 1 & $(6.2)$ & 15 & $(93.8)$ & \\
\hline
\end{tabular}

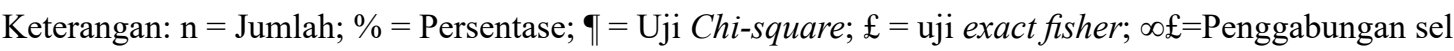

kelamin dan fungsi kognitif didapatkan nilai $\mathrm{p}=0.451$ yang artinya tidak terdapat hubungan yang bermakna secara statistik antara jenis kelamin dan fungsi kognitif. Penelitian Suriastini et al yang dilakukan di Yogyakarta melaporkan bahwa perempuan lebih banyak banyak menderita demensia dibandingkan dengan laki-laki. Hal ini berkaitan dengan usia harapan hidup perempuan lebih besar daripada laki-laki. ${ }^{(7)}$ Pada penelitian ini jumlah responden laki-laki lebih sedikit dibandingkan dengan perempuan dan dari data yang didapatkan dapat disimpulkan bahwa pada kejadian penurunan fungsi kognitif terjadi baik pada laki-laki maupun perempuan, meskipun pada perempuan angka kejadiannya lebih tinggi $6.5 \%$ dibandingkan dengan lakilaki.

Pada uji exact fisher antara pendidikan dengan fungsi kognitif didapatkan hasil nilai $\mathrm{p}=0.000$. Hasil tersebut menunjukkan bahwa terdapat hubungan yang bermakna antara pendidikan dan fungsi kognitif.
Hasil penelitian ini sesuai dengan studi oleh Lovden et al yang menyatakan bahwa tingkat pendidikan mempengaruhi fungsi kognitif pada masa dewasa dan menurunkan resiko terjadinya demensia pada usia lanjut, namun tidak mencegah terjadinya perubahan fungsi kognitif akibat proses penuaan. ${ }^{(26)}$ Pada penelitian ini dapat dilihat bahwa sebanyak 95.4\% responden dengan tingkat pendidikan rendah atau tidak bersekolah mengalami gangguan fungsi kognitif, sedangkan pada responden yang memiliki tingkat pendidikan lebih tinggi angka kejadian gangguan fungsi kognitif lebih rendah yaitu sebesar 52\%.

Hasil uji bivariat antara konsumsi susu dan fungsi kognitif menggunakan uji ChiSquare didapatkan hasil nilai $\mathrm{p}=0.660$ dan hal ini berarti bahwa tidak terdapat hubungan yang bermakna secara statisik antara konsumsi susu dengan fungsi kognitif. Hasil ini sejalan dengan temuan dari penelitian oleh Lee et $a l$, Petruski-Ivleva et al dan Cuesta-Triana et al yang menyimpulkan bahwa tidak ada 
hubungan antara konsumsi susu dengan fungsi kognitif. ${ }^{(14-16)}$ Sementara itu hasil penelitian Lei et al dan Ozawa et al menunjukkan hasil terdapat hubungan yang bermakna antara konsumsi susu dengan fungsi kognitif. ${ }^{(12,13)}$ Hasil yang berbeda ini dapat disebabkan karena perbedaan metodologi penelitian. Pada studi oleh Lei at al dan Ozawa et al dilakukan meta-analisis pada penelitian kohort yang pengamatannya berlangsung dalam kurun waktu yang lebih lama, sedangkan pada penelitian ini data hanya diambil dalam satu kali wawancara. Selain itu, studi oleh Lee et al menemukan bahwa pada 2 studi kohort dengan instrumen konsumsi susu yang berbeda, di mana salah satu studi menggunakan foodfrequency questionnaire, sedangkan studi lain melakukan pengukuran asupan susu dan produk susu selama 24 jam, memberikan hasil yang berbeda. Dalam studinya, Lee et al menganalisis penelitian yang mengukur fungsi kognitif menggunakan instrumen yang bervariasi misalnya MMSE, Deterioration Cognitive Observee (DECO) dan Instrumental Activities of Daily Living (IADL). Hasilnya didapatkan satu studi kohort menunjukkan hubungan yang bermakna antara konsumsi susu dengan penurunan fungsi kognitif, sedangkan dua studi lainnya mendapatkan hasil yang berbeda. Pada penelitian ini fungsi kognitif dinilai menggunakan kuesioner MoCA-Ina. Studi oleh Ciesielska et al menemukan bahwa tingkat sensitivitas dan spesifisitas kuesioner MoCA adalah 80.48\% dan $81.19 \%$, sedangkan untuk kuesioner MMSE adalah 66.34 dan 72.94\%. Studi tersebut menyatakan bahwa kuesioner MoCA lebih sensitif untuk mendeteksi adanya gangguan fungsi kognitif pada lansia berusia
60 tahun atau lebih jika dibandingkan dengan MMSE. Adanya perbedaan instrumen ini dapat menjadi salah satu sebab didapatkannya hasil yang berbeda. ${ }^{(27)}$

Penelitian ini mempunyai keterbatasan yaitu jumlah sampel penelitian yang digunakan hanya terbatas di Posyandu Lansia Kelurahan Krendang. Selain itu lansia yang menjadi responden sebagian besar mempunyai latar belakang pendidikan rendah yakni sekolah dasar. Untuk konsumsi susu, saat wawancara hanya ditanyakan jumlah mililiter susu yang dikonsumsi tanpa memperhatikan bentuk susu yang dikonsumsi apakah termasuk susu cair atau bubuk, serta takaran banyaknya tepung susu yang digunakan untuk setiap gelas susu. Penelitian inijugatidakmembedakan jenis susu yang dikonsumsi apakah susu skim ataupun full cream, serta tidak memperhitungkan produk turunan susu seperti keju dan yogurt. Faktor lain yang dapat menjadi perancu seperti kondisi sosioekonomi, status gizi, dan gangguan psikiatrik seperti depresi pada lansia pun belum diamati.

\section{KESIMPULAN}

Pada penelitian ini didapatkan bahwa tidak terdapat hubungan yang bermakna secara statistik antara konsumsi susu dan fungsi kognitif pada lansia. Selain itu, juga dapat disimpulkan tidak terdapat hubungan yang bermakna antara usia dan fungsi kognitif, dan antara jenis kelamin dan fungsi kognitif. Namun demikian, didapatkan hubungan yang bermakna secara statistik antara tingkat pendidikan dan fungsi kognitif. Dikarenakan adanya keterbatasan dalam penelitian ini, maka diperlukan penelitian lebih lanjut berkaitan dengan konsumsi susu 
dan fungsi kognitif dengan memperhatikan jenis dan takaran susu, serta asupan produk susu lainnya.

\section{UCAPAN TERIMA KASIH}

\section{Peneliti mengucapkan terima}

kasih kepada Bapak Andre Ravnic, S.STP

beserta staf kelurahan dan kader masyarakat

Krendang yang menyambut, memfasilitasi

dan memberi izin kepada peneliti, sehingga

dapat melaksanakan penelitian di Posyandu

Kelurahan Krendang, Jakarta Barat

\section{KONFLIK KEPENTINGAN}

Peneliti tidak memiliki konflik kepentingan terhadap hasil penelitian ini.

\section{REFERENSI}

1. Vega JN, Newhouse PA. Mild cognitive impairment: diagnosis, longitudinal course, and emerging treatments. Curr Psychiatry Rep. 2014;16(10):490. doi:10.1007/s11920-014-0490-8

2. Duong S, Patel T, Chang F. Dementia: What pharmacists need to know. Can $\mathrm{Ph}$ arm J (Ott) . $2017 ; 150$ (2):11829. P u b 1 i s h e d 20017 F e b 7 . doi:10.1177/1715163517690745

3. Pusat dan Informasi Kementerian Kesehatan RI. Analisis Lansia di Indonesia. Jakarta; 2017.

4. Noor CA, Merijanti LT. Hubungan antara aktivitas fisik dengan fungsi kognitif pada lansia. Jurnal Biomedika dan Kesehatan. 2020;3(1):8-14. doi: 10.18051/JbiomedKes.2020.v3.8-14

5. Alzheimer's Disease International. Dementia in the Asia Pacific Region. London; 2014.

6. Murman DL.The Impact of Age on Cognition. Seminars in hearing vol. 36,3 (2015): 111-21. doi: $10.1055 / \mathrm{s}-0035-1555115$

7. Suriastini NW, Turana Y, Witoelar F, et al. Policy Brief Angka Prevalensi Demensiam: Perlu Perhatian Kita Semua. SurveyMeter; 2016.

8. Baumgart M, Snyder HM, Carrillo MC, et al. Summary of the evidence on modifiable risk factors for cognitive decline and dementia: A population-based perspective. Alzheimers Dement. 2015;11(6):718-26. doi: 10.1016/j. jalz.2015.05.016

9. Hess JM, Jonnalagadda SS, Slavin JL. Dairy foods: current evidence of their effects on bone, cardiometabolic, cognitive, and digestive health. Compr Rev Food Sci Food Saf. 2016;15:251-68. doi: 10.1111/1541-4337.12183.

10. Sediaoetana DA. Ilmu Gizi Untuk Mahasiswa dan Profesi. Jakarta; Dian Rakyat. Jilid II. 2010. p.1335

11. Muehlhoff E, Bennett A, McMahon D. Milk and
Dairy Products in Human Nutrition. Rome: Food And Agriculture Organization; 2013.

12. Lei W, Dali S. Meta-analysis of milk consumption and the risk of cognitive disorders. Nutrients. 2016;8(12):824. doi: 10.3390/nu8120824

13. Ozawa M, Ohara T, Ninomiya T, et al. Milk and dairy consumption and risk of dementia in elderly Japanese population: the Hisayama study. J Am Geriatr Soc. 2014;62(7):1224-30. doi: 10.1111/ jgs. 12887

14. Lee JH, Fu ZX, Chung M, et al. Role of milk and dairy intake in cognitive function in oldr adults: a systematic review and meta-analysis. Nutr J. 2018;17(1):82. doi:10.1186/s12937-018-0387-1

15. Petruski-Ivleva N, Kucharska-Newton A, Palta P, et al. Milk intake at midlife and cognitive decline over 20 years. The Atherosclerosis Risk Communities (ARIC) Study. Nutrients. 2017;9(10):1134. doi: 10.3390/nu9101134

16. Cuesta-Triana D, Verdejo-Bravo C, FernandezPerez C, et al. Effect of milk and other dairy products on the risk of frailty, sarcopenia, and cognitive performance decline in the elderly: A systematic review. Adv Nutr. 2019;10(Suppl2):S105-S119. doi:10.1093/advances/nmy105

17. Akbar NL, Effendy E, Camellia V. The Indonesian version of Montreal Cognitive Assessment (MoCA-Ina): the difference scores between male schizophrenia prescribed by risperidone and adjunctive of donepezil in public hospital of dr. Pringadi Medan, Indonesia. Open Access Maced J Med Sci. 2019;7(11):1762-67. doi: 10.3889/ oamjms.2019.461.

18. Rambe AS, Fitri FI. Correlation between the Montreal Cognitive Assessment-Indonesian Version (Moca-INA) and the Mini-Mental State Examination (MMSE) in Elderly. Open Access Maced J Med Sci. 2017;5(7):915-919.Published 2017 Nov 25. doi:10.3889/oamjms.2017.202

19. Kitano N, Tsunoda K, Tsuji T, et al. Association between difficulty initiating sleep in older adults and the combination of leisure-time physical activity and consumption of milk and milk products: a cross-sectional study. BMC Geriatr. 2014;14:118. doi:10.1186/1471-2318-14-118.

20. Tim Survei Konsumsi Makanan Individu. Buku Foto Makanan.Pusat Teknologi Terapan Kesehatan dan Epidemiologi Klinik Badan Penelitian dan Pengembangan Kesehatan Kementerian Kesehatan Indonesia; 2014

21. Tanjung IK, Udiyono A, Kusariana N. Gambaran gangguan kognitif dan fungsional (IADL) pada lansian di kelurahan kramas, kecamatan Tembalang, kota Semarang. Jurnal Kesehatan Masyarakat [Internet]. 2019;7(1):168-75. Available from: https://ejournal3.undip.ac.id/ index.php/jkm/article/view/22866

22. Ihara M, Okamoto Y, Takahashi R. Suitability of the Montreal cognitive assessment versus the minimental state examination in detecting vascular cognitive impairment. J Stroke Cerebrovasc Dis. 2013;22(6):737-41. doi: 10.1016/j. jstrokecerebrovasdis.2012.01.001

23. Dong Y, Lee WY, Basri NA, et al. The Montreal Cognitive Assessment is superior to the MiniMental State Examination in detecting patients at higher risk of dementia. Int Psychogeriatr. 2012 Nov; 24(11):1749-55. doi: 10.1017/ S1041610212001068

24. Harada CN, Natelson Love MC, Triebel 
KL. Normal cognitive aging. Clin Geriatr Med. 2013;29(4):737-52. doi:10.1016/j. cger.2013.07.002

25. O'Shea A, Cohen RA, Porges EC, et al. Cognitive aging and the hippocampus in older adults. Front Aging Neurosci. 2016;8:298. doi: 10.3389/ fnagi.2016.00298

26. Lovden M, Fratiglioni L, Glymour MM, et al. Education and cognitive functioning across the life span. Psychol Sci Public Interest. 2020;21(1):6-41. doi: $10.1177 / 1529100620920576$.

27. Ciesielska N, Sokolowski R, Mazur E. Is the Montreal Cognitive Assessment (MoCA) test better suited than the Mini-Mental State Examination (MMSE) in mild cognitive impairment (MCI) detection among people aged over 60? Metaanalysis. Psychiatr. Pol. 2016;50(5):1039-52. doi: $10.12740 / \mathrm{PP} / 45368$ 